\title{
JOINT LOAD CONSIDERATIONS IN TOTAL KNEE REPLACEMENT
}

\author{
MARKUS S. KUSTER, GRAEME A. WOOD, GWIDON W. STACHOWIAK, ANDRÉ GÄCHTER
}

From the University of Western Australia, Australia

Estimates of knee joint loadings were calculated for 12 normal subjects from kinematic and kinetic measures obtained during both level and downhill walking. The maximum tibiofemoral compressive force reached an average load of 3.9 times body-weight (BW) for level walking and 8 times $\mathrm{BW}$ for downhill walking, in each instance during the early stance phase. Muscle forces contributed $80 \%$ of the maximum bone-on-bone force during downhill walking and $70 \%$ during level walking whereas the ground reaction forces contributed only $20 \%$ and $30 \%$ respectively.

Most total knee designs provide a tibiofemoral contact area of 100 to $300 \mathrm{~mm}^{2}$. The yield point of these polyethylene inlays will therefore be exceeded with each step during downhill walking. Future evaluation of total knee designs should be based on a tibiofemoral joint load of 3.5 times $\mathrm{BW}$ at $20^{\circ}$ knee flexion, 8 times $\mathrm{BW}$ at $40^{\circ}$ and 6 times $\mathrm{BW}$ at $60^{\circ}$.

J Bone Joint Surg [Br] 1997;79-B:109-13.

Received 6 June 1996; Accepted 24 September 1996

Several recent studies have reported severe wear of polyethylene tibial components. ${ }^{1-4}$ The long-term problems associated with joint wear debris, such as loosening and infection, are well known. Wear is dependent on a number of factors including contact area, load, material properties, thickness of the polyethylene inlay and the length of time that the component has been implanted. ${ }^{1,5}$ The most destructive wear process is fatigue, which occurs through

M. S. Kuster, MD, Orthopaedic Surgeon

A. Gächter, Professor and Chairman

Klinik für Orthopädische Chirurgie, Kantonsspital, 9007 St Gallen, Switzerland.

G. A. Wood, PhD, Associate Professor

Neuromuscular Performance Laboratory, Department of Human Movement

G. W. Stachowiak, PhD, Associated Professor

Tribology Laboratory, Department of Mechanical and Materials Engineering

The University of Western Australia, Nedlands, Australia 6907, Australia.

Correspondence should be sent to Dr M. S. Kuster.

(C)1997 British Editorial Society of Bone and Joint Surgery 0301-620X/97/16978\$2.00 repeated high loads and cyclic stressing. Load is dependent both on physical activity and on body-weight.

The increasing long-term successes being achieved with total knee replacement means that younger, and consequently more active, patients are being treated. This places an increased mechanical demand on the prosthesis which exceeds the design limits of many of the currently used devices.

The moments and forces about the knee vary substantially for different daily activities. ${ }^{6}$ Biomechanical studies of knee joint loading have consistently estimated maximum joint compressive forces to be about 4 to 4.5 times bodyweight during daily activities. ${ }^{7}$ This range of values has become a design criterion for most currently used knee prostheses, but recent studies have indicated that loadings can be much higher even during level walking. ${ }^{9,10}$ This finding is consistent with the increasing incidence of reports of severe wear in joint replacements. ${ }^{1,2,4,11-14}$ We present quantitative joint load data and suggest new criteria for use in the biomechanical evaluation of total knee prostheses.

\section{MATERIALS AND METHODS}

We obtained estimates of knee joint loading for 12 normal subjects (6 male and 6 female) ranging in age from 23 to 37 years (mean 27.9), in height from 158 to $187 \mathrm{~cm}$ (mean 171) and in weight from 49 to $90 \mathrm{~kg}$ (mean 70.8). Reflective markers were located superficial to the 5th metatarsophalangeal, ankle, knee and hip joints. Spatial trajectories were recorded using a video-based motion analysis system with two cameras sampling at $60 \mathrm{~Hz}$ (APAS, Ariel Dynamics, Inc, Trabuco Canyon, California) whilst the subjects walked across a level floor and down a purpose-built ramp of $19 \%$ gradient. Ground reaction force data were simultaneously obtained from a Kistler force platform (Type 9281B, Winterhur, Switzerland). Ground reaction forces during downhill walking were measured using an aluminium plate bolted to the force platform. Step frequency for both downhill and level walking was controlled by means of a metronome set at $120 \mathrm{steps} / \mathrm{min}$.

The marker trajectories in the sagittal plane were smoothed using a Butterworth 4th-order low-pass digital filter with a cut off frequency of $7 \mathrm{~Hz}$ prior to the derivation of segmental orientations and centre of mass locations. Time derivatives of these measures were then calculated by finite differences. Finally, planar joint reaction forces and net 
joint moments at the ankle, knee and hip were estimated from these kinematic data and force platform measures using standard inverse dynamics procedures and anthropometric values from Winter. ${ }^{15}$

A knee joint model, previously described by Nisell, ${ }^{16}$ was then used to calculate the tibiofemoral (bone-on-bone) force from the mean joint reaction forces and knee extensor moments which had been derived from the inverse dynamic analysis. The total uncertainty based on the standard error of the mean of the peak bone-on-force was calculated as outlined by Campion. ${ }^{17}$ Full details of the instrumentation used can be found in the authors' previously published work. $^{18,19}$

\section{RESULTS}

The highest knee joint loadings occurred during downhill walking. The peak joint moments occurred at $41 \pm 6^{\circ}$ knee flexion and were $2.75 \pm 0.5 \mathrm{Nm} / \mathrm{kg}$ for females and $2.70 \pm$ $0.7 \mathrm{Nm} / \mathrm{kg}$ for males. The vertical joint reaction forces were $15.2 \pm 1.6 \mathrm{~N} / \mathrm{kg}$ for females and $15.5 \pm 1.9 \mathrm{~N} / \mathrm{kg}$ for males. The kinetic and kinematic data for males and females were not significantly different $(p>0.85)$. The joint model used in this investigation defined the lever arm of the quadriceps muscles of female subjects as being significantly smaller than that of male subjects. Thus the actual tibiofemoral model predictions were consistently smaller for male subjects. The peak tibiofemoral force for male subjects was 7 times BW during downhill walking, whereas it reached 8 times BW for female subjects. Values obtained for level walking (at $20^{\circ}$ knee flexion) were approximately $50 \%$ of those for downhill walking giving values of 3.4 times $\mathrm{BW}$ for male and 3.9 times $\mathrm{BW}$ for female subjects. The standard error of the mean in the prediction of peak force was calculated to be $13 \%$ for level and downhill walking. The mean female knee joint compressive forces for the duration of the support phase during downhill walking and level walking are shown in Figure 1. The bone-on-bone compressive forces are shown as are the muscle and gravitational force (ground reaction force) contributions to this load. As can be seen from Figure 1, extensor muscle force is by far the greatest contributor to the joint compressive force during level $(70 \%)$ and downhill $(80 \%)$ walking.

From the estimated knee joint loads, we calculated the stress on the tibial plateau for a $70 \mathrm{~kg}$ female in several walking tasks, plotted against varying tibiofemoral contact area, assuming a uniform pressure distribution. The results are shown in Figure 2, together with an indication of the yield range for ultra high molecular weight polyethylene (UHMWPE). It is clear that in order to obtain stress levels which are safely below the yield point of UHMWPE for all

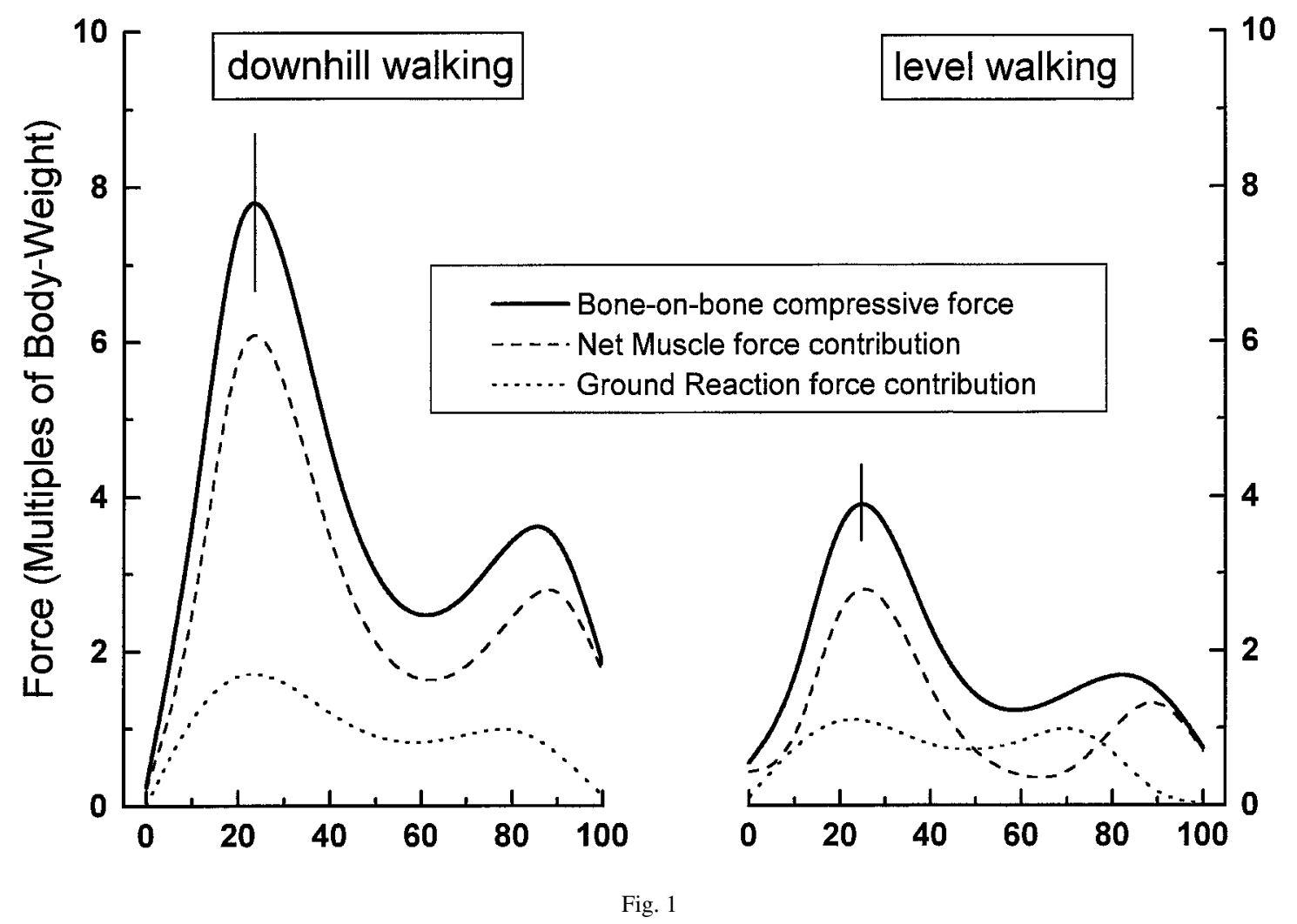

Mean tibiofemoral joint loadings of the six female subjects during the stance phase in level and downhill walking. The values are reported in multiples of body-weight (BW) and normalised to $100 \%$ of the stance time. Heel strike occurs at $0 \%$ and toe-off at $100 \%$. The total uncertainty (SEOM) is indicated for the peak tibiofemoral compressive force values. 


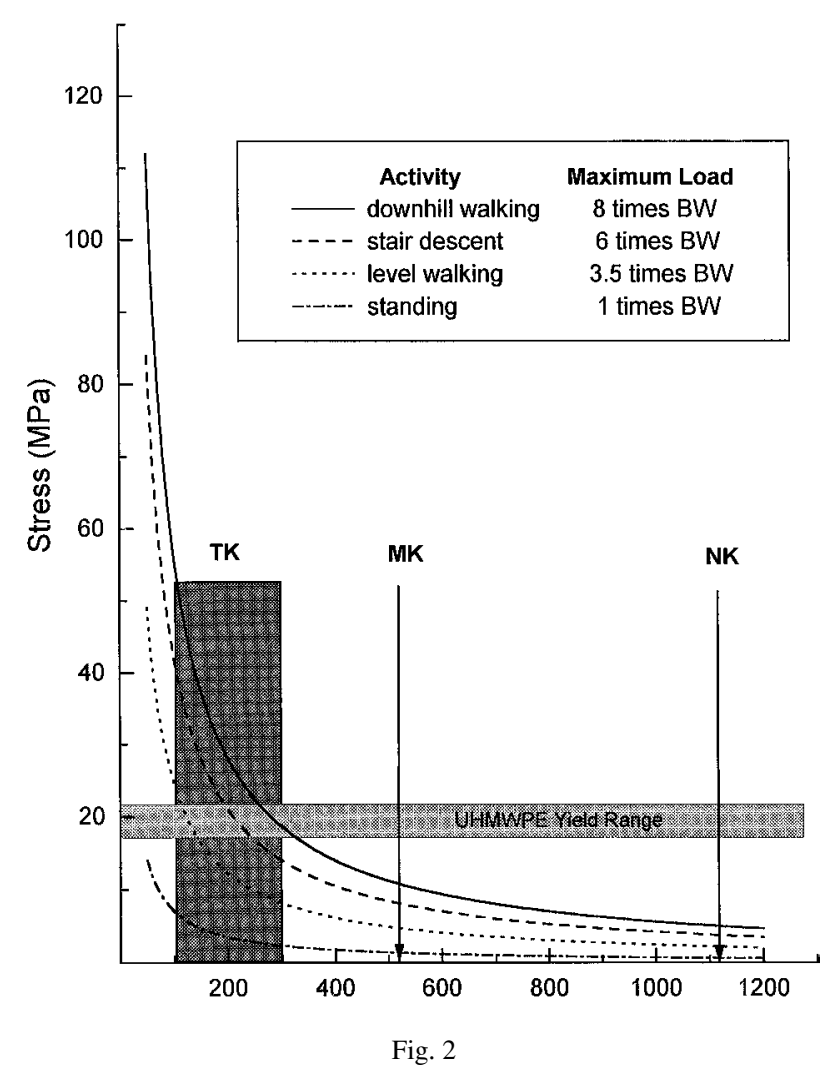

Plot of the tibial plateau stress versus the contact area for different daily activities for a $70 \mathrm{~kg}$ female subject. A uniform stress distribution is assumed. The range of tibiofemoral contact area of current knee prostheses $^{31}$ (TK), a knee joint after meniscectomy ${ }^{30}$ (MK) and a natural knee joint $^{30}(\mathrm{NK})$ are shown. The horizontal bar indicates the yield range of polyethylene.

daily activities a contact area greater than $400 \mathrm{~mm}^{2}$ is required.

\section{DISCUSSION}

This study demonstrates that the muscle forces contribute $80 \%$ of the maximum bone-on-bone force during downhill walking and $70 \%$ of the maximum bone-on-bone force during level walking. The magnitude of the ground reaction force is not the best predictor of the joint load, the muscle moments are more reliable. These patellar ligament forces are based on calculations of the net muscle moment of force acting about the knee, which is a limitation of the inverse dynamics approach. Quadriceps effort required to overcome antagonistic effects of the knee flexor muscles is not included. Electromyographic activity, recorded from our subjects during their downhill walking, clearly indicated the presence of hamstring, gastrocnemius and quadriceps muscle co-activity during the stance phase. ${ }^{19}$ The measures of joint compression reported here are therefore conservative estimates but still exceed eight times bodyweight for downhill walking.

Force values equivalent to three to four times BW have previously been used in most biomechanical tests evaluat- ing total knee replacements. ${ }^{11,20,21}$ Estimates of the tibiofemoral bone-on-bone forces in our study were close to four times BW even during level walking and more than eight times BW during downhill walking. Collins ${ }^{9}$ calculated the knee joint loads during level walking using an optimisation method which incorporated muscle coactivation of agonists and antagonists. He concluded that the tibiofemoral loads range from 3.9 to 6.0 times BW. Jefferson et al ${ }^{10}$ found that the maximum tibiofemoral loads are up to 6.3 times BW, while Wyss et $\mathrm{al}^{22}$ report values ranging from 2.5 to 5 times BW. Our results for level walking are well within the limits of these predictions. As the experimental set-up for level and downhill walking did not change, the calculated loads for downhill walking, allowing for the angulation of the plate, present a valid comparison.

Loads for biomechanical evaluation of patellar components have been considered to be in the range of 0.7 to 2 times BW. ${ }^{23}$ Some researchers, in order to evaluate different designs, assumed loads as low as 0.15 times BW for level walking and 2.2 times BW for walking downstairs. ${ }^{24}$ Recent research indicates higher loadings; for level walking patellofemoral joint forces of 1.3 to 1.8 times $\mathrm{BW},{ }^{16,25}$ for downstairs walking 5.5 times $\mathrm{BW}^{16}$ and for downhill walking 5 to 7 times BW have been suggested. ${ }^{25}$ For some sports activities such as jumping ${ }^{26}$ or weightlifting ${ }^{27}$ the loads imposed on the patellofemoral joint are close to 20 times BW.

A review of the available literature indicates that the majority of authors use the lowest tibiofemoral and patellofemoral joint loads reported for the evaluation of contact stresses in total joint replacement. ${ }^{5,11,21,23,24,28}$ In order to improve the design of total knee replacements, it is necessary to adopt higher tibiofemoral and patellofemoral loads.

Contact area has a very profound effect on joint stress (Fig. 2). The reported average contact area of a natural knee joint ranges from $765 \mathrm{~mm}^{2}$ to $1150 \mathrm{~mm}^{2}$. $^{30}$ After complete medial and lateral meniscectomy the tibiofemoral contact area is approximately $520 \mathrm{~mm}^{2}$, depending on the load. ${ }^{29,30}$ Assuming a uniform load distribution and a load of eight times BW the estimated stress on the articular cartilage is only about $10 \mathrm{MPa}$ for a knee joint without menisci and less than $5 \mathrm{MPa}$ for a healthy knee. The contact area of most total knee prostheses is between 80 and $300 \mathrm{~mm}^{2}$ depending on the load, flexion angle and design, ${ }^{31}$ leading to contact stresses on the UHMWPE inlay as high as $60 \mathrm{MPa}$; this exceeds the yield point of $20 \mathrm{MPa}$ for UHMWPE.

A contact area of approximately $400 \mathrm{~mm}^{2}$ is necessary to avoid stresses to the polyethylene inlay that are above the yield point of $20 \mathrm{MPa}$. This contact area should be maintained throughout a flexion range of $0^{\circ}$ to $60^{\circ}$ to accommodate the high loads of downhill and downstairs walking. Congruent prostheses significantly reduce polyethylene wear, and line or point contact should be avoided. ${ }^{32,33}$

In summary, the design of knee replacements should allow for the much higher joint loadings now being estimated through gait analysis if severe wear is to be avoided. 
Table I. Reported tibiofemoral joint loads for several daily activities

\begin{tabular}{lll}
\hline Author(s) & Activity & $\begin{array}{l}\text { Tibiofemoral joint load } \\
\text { (body-weight multiples) }\end{array}$ \\
\hline Ericson and Nisell $^{34}$ & Cycling & 1.2 \\
Morrison $^{8}$ & Level walking & 3.0 \\
Harrington $^{35}$ & & 3.5 \\
Present $^{3}$ study & & 3.9 \\
Collins $^{7}$ & & 3.9 to 6.0 \\
Morrison $^{7}$ & Downstairs walking & 3.8 \\
Andriacchi $^{36}$ & & 6 \\
Morrison $^{7}$ & Downhill walking & 4.5 \\
Present study $^{37}$ & & 8 \\
Ellis $^{16}$ & Rising from chair & 3.2 \\
Nisell $^{16}$ & Isokinetic knee extension & 9 \\
& at $30^{\circ} /$ sec & \\
Dahlkvist $^{38}$ & Squat descent & up to 24 \\
Collins $^{39}$ & Weightlifting (120 kg) & \\
\hline
\end{tabular}

Table II. Reported patellofemoral joint loads for several daily activities (NB: where the data for the joint load calculations were taken from secondary sources then these are indicated in parentheses)

\begin{tabular}{|c|c|c|}
\hline Author & Activity & $\begin{array}{l}\text { Patellofemoral joint load } \\
\text { (body-weight multiples) }\end{array}$ \\
\hline Ericson et $\mathrm{al}^{40}$ & Cycling & 1.2 \\
\hline $\begin{array}{l}\text { Reilly and Martens } \\
\left.\text { Matthews }^{42} \text { (Morrison }^{8}\right) \\
\left.\text { Nisell }^{16}{ }^{25} \text { Boccardi }^{43}\right) \\
\text { Kuster }^{25}\end{array}$ & Level walking & $\begin{array}{l}0.5 \\
0.7 \\
1.3 \\
1.8\end{array}$ \\
\hline $\begin{array}{l}\text { Nisell }^{16} \text { (Andriacchi }^{36} \text { ) } \\
\text { Reilly and Martens } \\
\text { Matthews }^{42} \text { (Morrison }^{44} \text { ) }\end{array}$ & Stair ascending & $\begin{array}{l}2.1 \\
3.3 \\
2.5\end{array}$ \\
\hline $\begin{array}{l}\text { Nisell }^{16} \text { (Andriacchi }^{36}{ }^{4} \text { ) } \\
\text { Reilly and Martens } \\
\text { Matthews }^{42} \text { (Morrison }^{44} \text { ) }\end{array}$ & Stair descending & $\begin{array}{l}5.6 \\
3.3 \\
2.5\end{array}$ \\
\hline $\begin{array}{l}\text { Matthews } \\
\text { Kuster }^{25}\end{array}$ & Downhill walking & $\begin{array}{l}1.8 \\
7.0\end{array}$ \\
\hline Ellis $^{37}$ & Rising from chair & 3.1 \\
\hline Nisell $^{16}$ (Winter ${ }^{45}$ ) & Jogging & 7.0 \\
\hline Dahlkvist $^{38}$ & Squat descent & 7.6 \\
\hline Huberti ${ }^{46}$ & $\begin{array}{l}\text { Isometric contraction at } \\
90^{\circ} \text { flexion }\end{array}$ & 6.5 \\
\hline Nisell $^{47}$ & $\begin{array}{l}\text { Isokinetic exercise at } \\
30 \% / \mathrm{sec}\end{array}$ & 12.0 \\
\hline Nisell $^{16}$ (Wahrenberg ${ }^{48}$ ) & Kicking & 7.6 \\
\hline Zernicke $^{27}$ & Patellar tendon rupture & $17.5-25$ \\
\hline
\end{tabular}

No benefits in any form have been received or will be received from a commercial party related directly or indirectly to the subject of this article.

\section{REFERENCES}

1. Engh GA, Dwyer KA, Hanes CK. Polyethylene wear of metalbacked tibial components in total and unicompartmental knee prostheses. J Bone Joint Surg [Br] 1992;74-B:9-17.

2. Engh GA. Failure of the polyethylene bearing surface of a total knee replacement within four years: a case report. J Bone Joint Surg [Am] 1988;70-A:1093-6.

3. Lindstrand A, Ryd L, Stenström A. Polyethylene failure in two total knees: wear of thin, metal-backed PCA tibial components. Acta Orthop Scand 1990;61-:575-7.
4. Jones SMG, Pinder IM, Moran CG, Malcolm AJ. Polyethylene wear in uncemented knee replacements. J Bone Joint Surg [Br] 1992;74-B:18-22.

5. Bartel DL, Bicknell VL, Wright TM. The effect of conformity, thickness and material on stresses in ultra-high molecular weight components for total joint replacement. J Bone Joint Surg [Am] 1986;68-A:1041-51.

6. Andriacchi PT, Mikosz RP. Musculoskeletal dynamics, locomotion and clinical applications. In: Mow VC, Hayes WC, ed. Basic Orthopaedic Biomechanics. New York, Raven Press, 1991:51-92.

7. Morrison JB. Function of the knee joint in various activities. Biomed Engin 1969;4:573-80.

8. Morrison JB. The mechanics of the knee joint in relation to normal walking. J Biomech 1970;3:51-61. 
9. Collins JJ. The redundant nature of locomotor optimization laws. J Biomech 1995;28:251-67.

10. Jefferson RJ, Collins JJ, Whittle MW, Radin EL, O'Connor JJ. The role of the quadriceps in controlling impulsive forces around heel strike. Proc Inst Mech Eng H 1990;204:21-8.

11. Collier JP, Mayor MB, McNamara JL, Suprenant VA, Jensen RE. Analysis of the failure of 122 polyethylene inserts from uncemented tibial knee components. Clin Orthop 1991;273:232-42.

12. Mintz L, Tsao AK, McCrae CR, Stulberg SD, Wright T. The arthroscopic evaluation and characteristics of severe polyethylene wear in total knee arthroplasty. Clin Orthop 1991;273:215-22.

13. Kilgus DJ, Moreland JR, Finerman GA, Funahashi TT, Tipton JS. Catastrophic wear of tibial polyethylene inserts. Clin Orthop 1991;273:223-31.

14. Wasielewski RC, Galante JO, Leighty RM, Natarajan RN, Rosenberg AG. Wear patterns on retreived polyethylene tibial inserts and their relationship to technical considerations during total knee arthroplasty. Clin Orthop 1994;299:31-43.

15. Winter DA. Biomechanics and motor control of human movement. 2nd ed. New York, John Wiley, 1990.

16. Nisell R. Mechanics of the knee: a study of joint and muscle load with clinical applications. Acta Orthop Scand 1985;56:[Supp] 216.

17. Campion PJ, Burns JE, Williams A. A code of practise for the detailed statement of accuracy. National Physics Laboratory Publication, London, Her Majesty's Stationery Office, 1973.

18. Kuster M, Sakurai S, Wood G A. Kinematic and kinetic comparison of downhill and level walking. Clin Biomech 1995;10:79-84.

19. Kuster M, Sakurai S, Wood G A. Downhill walking: a stressful task for the anterior cruciate ligament? Knee Surg Sports Traumatol Arthroscopy 1994;2:2-7.

20. Walker PS. Requirements for successful total knee replacements: design considerations. Orthop Clin North Am 1989;20:15-29.

21. McNamara JL, Collier JP, Mayor MB, Jensen RE. A comparison of contact pressures in tibial and patellar total knee components before and after service in vivo. Clin Orthop 1994;299:104-13.

22. Wyss UP, Costigan PA, Li J, Olney SJ, Zee BC, Cooke TDV. Boneon-bone forces at the knee joint during walking and stairclimbing. Proc XIVth Congress of ISB, Paris 1993:1482-3.

23. Collier JP, McNamara JL, Suprenant VA, Jensen RE, Suprenant HP. All-polyethylene patellar components are not the answer. Clin Orthop 1991;273:198-203.

24. Buechel FF, Pappas MJ, Makris G. Evaluation of contact stress in metal-backed patellar replacements: a predictor of survivorship. Clin Orthop 1991;273:190-7.

25. Kuster M, Wood GA, Sakurai S, Blatter G. Stress on the femoropatellar joint in downhill walking: a biomechanical study. Z Unfallchir Versicherungsmed 1993;86:178-83.

26. Smith AJ. A study of forces on the body in athletic events with particular reference to jumping. PhD Thesis, Leeds, England, 1972.

27. Zernicke RF, Garhammer J, Jobe FW. Human patellar-tendon rupture: a kinetic analysis. J Bone Joint Surg [Am] 1977;59-A: 179-83.
28. Bartel DL, Rawlison JJ, Burstein AH, Ranawat CS, Flynn WF Jr. Stresses in polyethylene components of contemporary total knee replacements. Clin Orthop 1995;317:76-82.

29. Kettelkamp DB, Jacobs AW. Tibiofemoral contact area: determination and implications. J Bone Joint Surg [Am] 1972;54-A:349-56.

30. Fukubayashi T, Kurosawa $H$. The contact area and pressure distribution pattern of the knee. Acta Orthop Scand 1980;51:871-9.

31. Postak PD, Heim CS, Greenwald AS. Tibial plateau surface stress in TKA: a factor influencing polymer failure. AAOS 1994.

32. Argenson JN, O'Connor JJ. Polyethylene wear in meniscal knee replacement: a one to nine-year retrieval analysis of the Oxford knee. J Bone Joint Surg [Br] 1992;74-B:228-32.

33. Plante-Bordeneuve P, Freeman MAR. Tibial high-density polyethylene wear in conforming tibiofemoral prostheses. J Bone Joint Surg [Br] 1993;75-B:630-6.

34. Ericson MO, Nisell R. Tibiofemoral joint forces during ergometer cycling. Am J Sports Med 1986;14:285-90.

35. Harrington IJ. A bioengineering analysis of force actions at the knee in normal and pathological gait. Biomed Eng 1976;11:167-72.

36. Andriacchi PT, Andersson GBJ, Fermier RW, Stern D, Galante JO. A study of lower-limb mechanics during stair-climbing. $J$ Bone Joint Surg [Am] 1980;62-A:749-57.

37, Ellis MI, Seedhom BB, Wright V. Forces in the knee joint whilst rising from a seated position. J Biomed Eng 1984;6:113-20.

38. Dahlkvist NJ, Mayo P, Seedhom BB. Forces during squatting and rising from a deep squat. Eng Med 1982;11:69-76.

39. Collins JJ. Antagonistic-synergistic muscle action at the knee during competitive weight lifting. Med Biol Eng Comput 1994;32:168-74.

40. Ericson MO, Nisell R. Patellofemoral joint forces during ergometric cycling. Phys Ther 1987;67:1365-69.

41. Reilly DT, Martens M. Experimental analysis of the quadriceps muscle force and patello-femoral joint reaction force for various activities. Acta Orthop Scand 1972;43:126-37.

42. Matthews LS, Sonstegard DA, Henke JA. Load bearing characteristics of the patello-femoral joint. Acta Orthop Scand 1977;48:511-6.

43. Boccardi S, Pedotti A, Rodano R, Santambrogio GC. Evaluation of muscular moments at the lower limb joints by an on-line processing of kinematic data and ground reaction. J Biomech 1981;14:35-45.

44. Morrison JB. The mechanics of the knee joint in relation to normal walking. J Biomech 1970;3:51-61.

45. Winter DA. Moments of force and mechanical power in jogging. J Biomech 1983;16:91-7.

46. Huberti HH, Hayes WC. Patellofemoral contact pressures: the influence of Q-angle and tendofemoral contact. J Bone Joint Surg [Am] 1984;66-A:715-24.

47. Nisell R, Ericson M. Patellar forces during isokinetic knee extension. Clin Biomech 1992;7:104-8.

48. Wahrenberg H, Lindbeck L, Ekholm J. Knee muscular moment, tendon tensio force and EMG during a vigorous movement in man. Scand J Rehabil Med 1978;10:99-106. 